\title{
Wann das Gehirn am meisten reift
}

\author{
Das Gehirn des Menschen unter- \\ scheidet sich stark vom Gehirn ande- \\ rer Primaten: Es ist überproportional \\ groß, aber auch anders aufgebaut \\ und strukturiert. Unklar ist, warum \\ das Denkorgan gerade beim Homo \\ sapiens so ausgeprägt ist und wie \\ diese Entwicklung verläuft.
}

- Wissenschaftler des Primatenforschungsinstituts der University of Kyoto in Aichi (Japan) analysierten die Hirnentwicklung von heranwachsenden Menschen, Schimpansen und Rhesusaffen per MRT.

Das Gehirn von Rhesusaffen erreicht schon in der frühen Kindheit seine vollständige Größe. Bei Schimpansen und Menschen reift es dagegen verzögert heran. Das stärkste Gehirnwachstum zeigte sich beim Menschen im Alter von zwölf bis 24 Monaten. In dieser Phase nahm die weiße Substanz beim Menschen um $43 \%$ zu, beim Schimpansen lediglich um $17 \%$.

- T. Sakai et al.

Developmental patterns of chimpanzee cerebral tissues provide important clues for understanding the remarkable enlargement of the human brain. Published online Dec 19, 2012; doi: 10.1098/rspb.2012.2398

\section{Kommentar}

Eine verzögerte Reifung des Gehirns findet sich sowohl beim Menschen als auch beim Schimpansen. Anders aber als beim nahe verwandten Affen zeigen sich im menschlichen Gehirn im zweiten Lebensjahr auch noch dramatische Strukturveränderungen. Die weiße Substanz, die beim Menschen im zweiten Lebensjahr wesentlich an Volumen zunimmt, ist verantwortlich für die Vernetzung der verschiedenen Hirnareale. Möglicherweise ist es dieser Unterschied in der Gehirnreifung, der evolutionär vom Menschenaffen zum Menschen geführt hat 